\title{
Environmental Variability and Chum Salmon Production at the Northwestern Pacific Ocean
}

\author{
Suam Kim¹, Sukyung Kang 2 , Ju Kyoung Kim ${ }^{3}$, and Minkyoung Bang ${ }^{4}$ \\ ${ }^{I}$ Department of Marine Biology, College of Fisheries Sciences, Pukyong National University, Busan 48513, Korea \\ ${ }^{2}$ Fisheries Resources Management Division, National Institute of Fisheries Science, Busan 46083, Korea \\ ${ }^{3}$ Inland Life Resources Center, Korea Fisheries Resources Agency, Yangyang 25041, Korea \\ ${ }^{4}$ Ocean Circulation and Climate Research Center, KIOST, Ansan 15627, Korea
}

Keywords: chum salmon, North Pacific, Korean waters, climate change, Pacific Decadal Oscillation (PDO)

\section{Introduction}

Chum salmon have the widest distribution range among Pacific salmon species, but the main populations occupy the northwestern Pacific Ocean. Spawning rivers of Asian chum salmon are spread over Russian, Japanese, and Korean territories, and the middle part of the eastern Korean Peninsula is the southern limit of the chum salmon distribution (Fig. 1a).

Events of decadal-scale climate change, frequently called the climate regime shift and expressed by the index known as Pacific Decadal Oscillation (PDO), were reported in the mid-1940s and the mid-1970s in the North Pacific (Fig. 1b), and the changing patterns in the catches of pink salmon matched well with that of climate regime shifts through the 20th century (Francis and Hare 1994; Hare and Mantua 2000). In general, a positive anomaly of the PDO index tends to reflect a warm environment in the eastern and northern Pacific, while a positive anomaly reflects a cool environment in the central and western Pacific (Fig. 1c and d).

In this paper, we investigate the relationship between climate and environmental variability, enhancement program, and chum salmon production in the northwestern Pacific Ocean. Our special interests are also focused on controlling factors that determine the return rate of chum salmon in Korean waters. Results of our analysis may be helpful in enhancing ecological knowledge and improving fishery management under changing climate conditions.

\section{Materials and Methods}

To investigate the relationship between survival of chum salmon and environmental conditions, the large-scale climate indices PDO (http://jisao.washington.edu/pdo/PDO.latest) were used in this paper, during the 1925-2014 period. For the habitat environment of salmon fry in Korean waters, two sources of seawater temperatures were available. One is survey data from the National Institute of Fisheries Science (NIFS, formerly known as the National Fisheries Research and Development Institute) and another data is seawater temperature that was measured at the Sokcho Light House which is located the nearest to the releasing point of chum salmon fry during the springtime (Fig. 1a). Offspring from a single spawning year return to their natal streams within 2 to 5 years, and age 6 and older are very few (Seo et al. 2006), so that we considered only age 2 through to 5 for the calculation of chum salmon return rate. The summation of different returns divided by total release is the return rate of chum salmon in a specific year. The formula used for this calculation is

$$
R_{i}=\frac{\left(a g e 2_{-} p \times c_{i+1}\right)+\left(a g e 3_{-} p \times c_{i+2}\right)+\left(a g e 4_{-} p \times c_{i+3}\right)+\left(a g e 5_{-} p \times c_{i+4}\right)}{\text { release } \boldsymbol{i}}
$$

where $\mathrm{Ri}$ is the return rate of chum salmon released in year $\mathrm{i}$, release $\mathrm{i}$ is the number of fry released in year $\mathrm{i}$, $c i+1$ is the number of chum salmon returning to a natal river in year $i+1$, and age $2 \_p$ is the proportion of Age-2 salmon, etc.

To detect long-term trends or climate and ecosystem regime shifts visually, we used the Cumulative Summation (CuSum). The Sequential Regime Shift Detector (SRSD) developed by Rodionov (2005) was used to detect the discontinuities in time series. Cross-Correlation Function (CCF) analysis was used to examine the lagged relationship between climatic/ environmental factors and chum salmon catches.

\section{Results}

The characteristics of environmental variability were examined by the changing pattern of seawater temperature which varies geographically and temporally at each habitat region of chum salmon in the northwestern Pacific. The Okhotsk Sea and the Bering Sea which are the main residence areas of immature chum salmon did not 
demonstrate the same temperature pattern as the western North Pacific in Korean and Japanese waters (Fig. 1c and d).
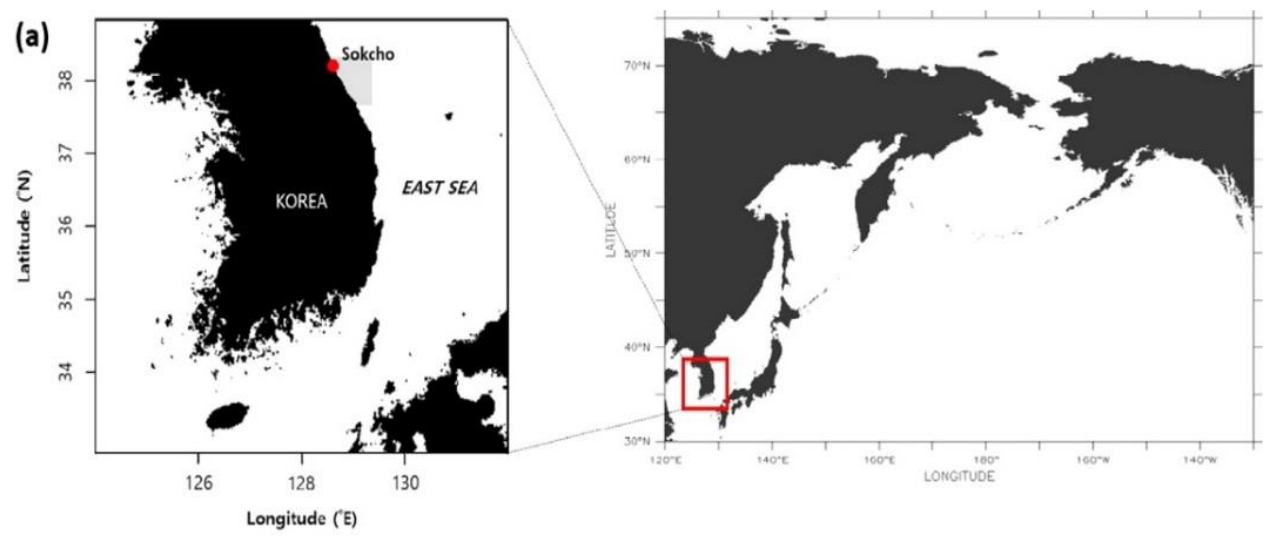

(b)

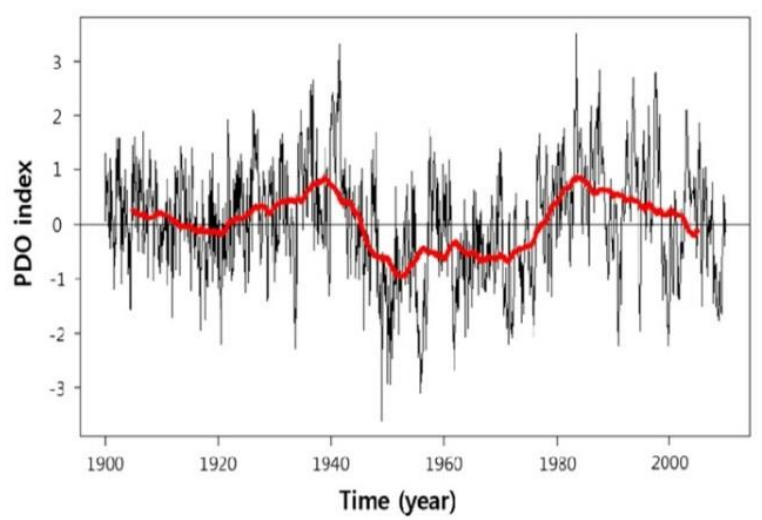

(c)

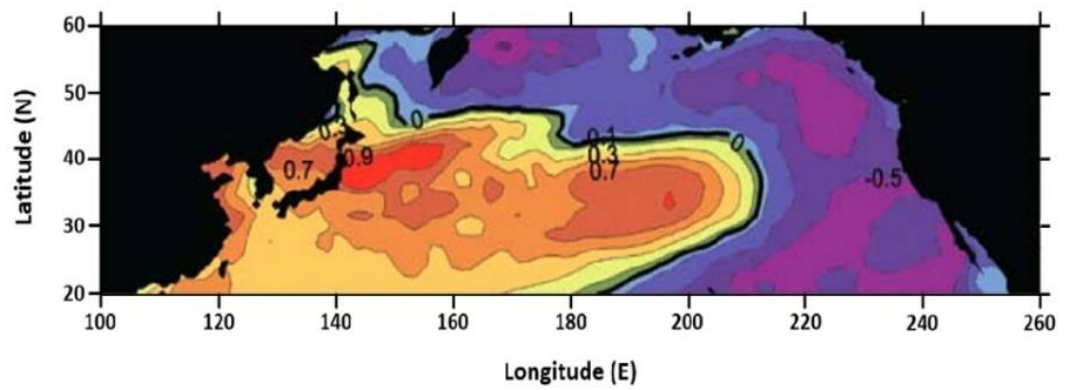

(d)

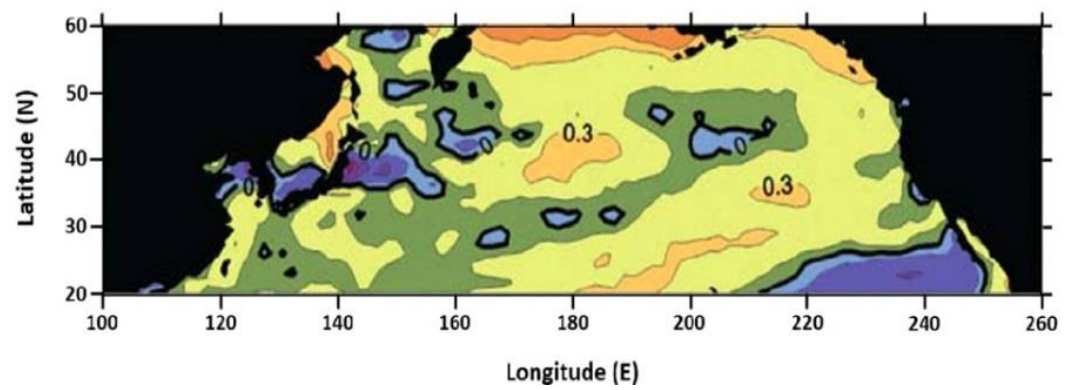

Fig. 1. Study area and environmental variability used in this study. (a) Seawater temperatures were collected from the ocean monitoring area (shaded) and the Sokcho Lighthouse (white dot) in Korean waters, (b) monthly values of the Pacific Decadal Oscillation Index, 1900-2009. Red line indicates 10-year moving average, (c) average sea surface temperature anomalies during negative PDO, May 1998-August 2002, and (d) average sea surface temperature anomalies during positive PDO, September 2002- September 2007 (McKinnell et al. 2010). 


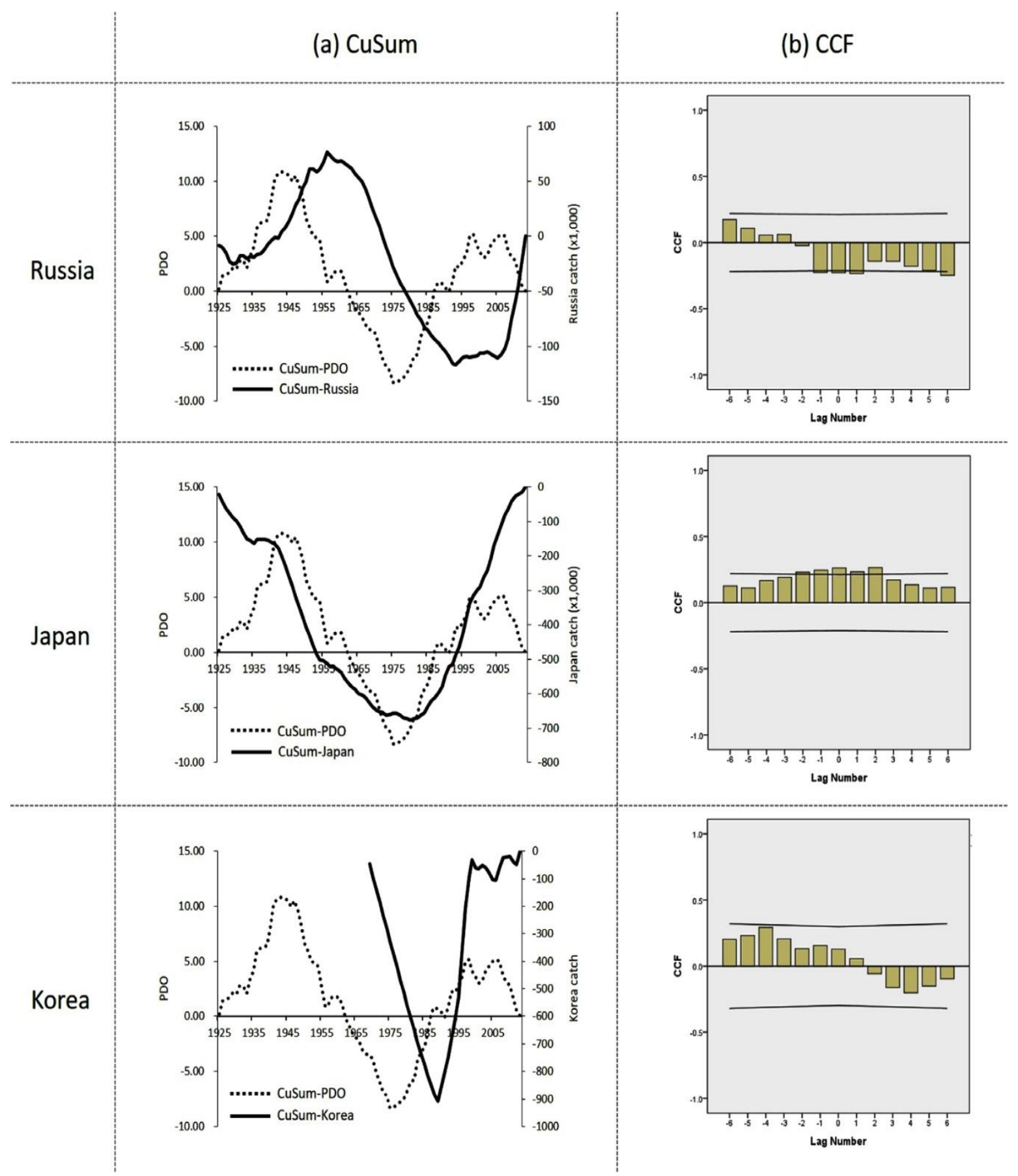

Fig. 2. Relationship between environmental variability and chum salmon catch. (a) Trend of Cumulative Summation (CuSum) of regional chum salmon catches (thin lines) and Pacific Decadal Oscillation indices (dotted lines) during 1925 2012, and (b) Cross-Correlation Function (CCF) analysis on Pacific Decadal Oscillation index and chum salmon catches.

The CuSum plots on the time-series PDO index revealed the big changes happened in the mid-1940s and 1970s, with a relatively small change in the late 1990s, showing that the 1976/77 climate regime shift was one of the strongest events in the 20th century (Fig. 2a). The CuSum curve for Russian chum salmon catch revealed a turning point in the late 1980s after one to two decades of climate regime shift in the 1970s. A similar relationship was 
found in an earlier period during the 1940s through to the 1950s. The CuSum curve from Japanese chum salmon, however, indicated a turning point in the late 1970s right after the turning point of the PDO in mid-1970s, although no matched turning points in catch and PDO were found in the 1940s and 1990s. For Korean stock, due to the lack of longer catch statistics, we could not see any relationship between climate index and catch. Each regional stock in the western Pacific showed a different correlation on chum salmon catch and PDO. The CCF analysis indicated that significant negative correlations between PDO and Russian stock were found with a time-lag of 0 and 1 year. For Japanese stock, however, correlations were positive for 6 years, and statistical significances were found in the timelag of 0 through 2 years. Korean stock also showed positive correlations with time like the Japanese one, but there was no statistical significance through 6 years (Fig. 2b). As shown in Figures 3c and 3d, it has been frequently observed that seawater temperatures in northern (i.e., off the Kamchatka Peninsula of Russian waters) and southern (i.e., Japanese and Korean waters) waters were opposite, which indicates that low seawater temperature at juvenile habitats are beneficial to chum salmon production with a time-lag of 0-1 years.
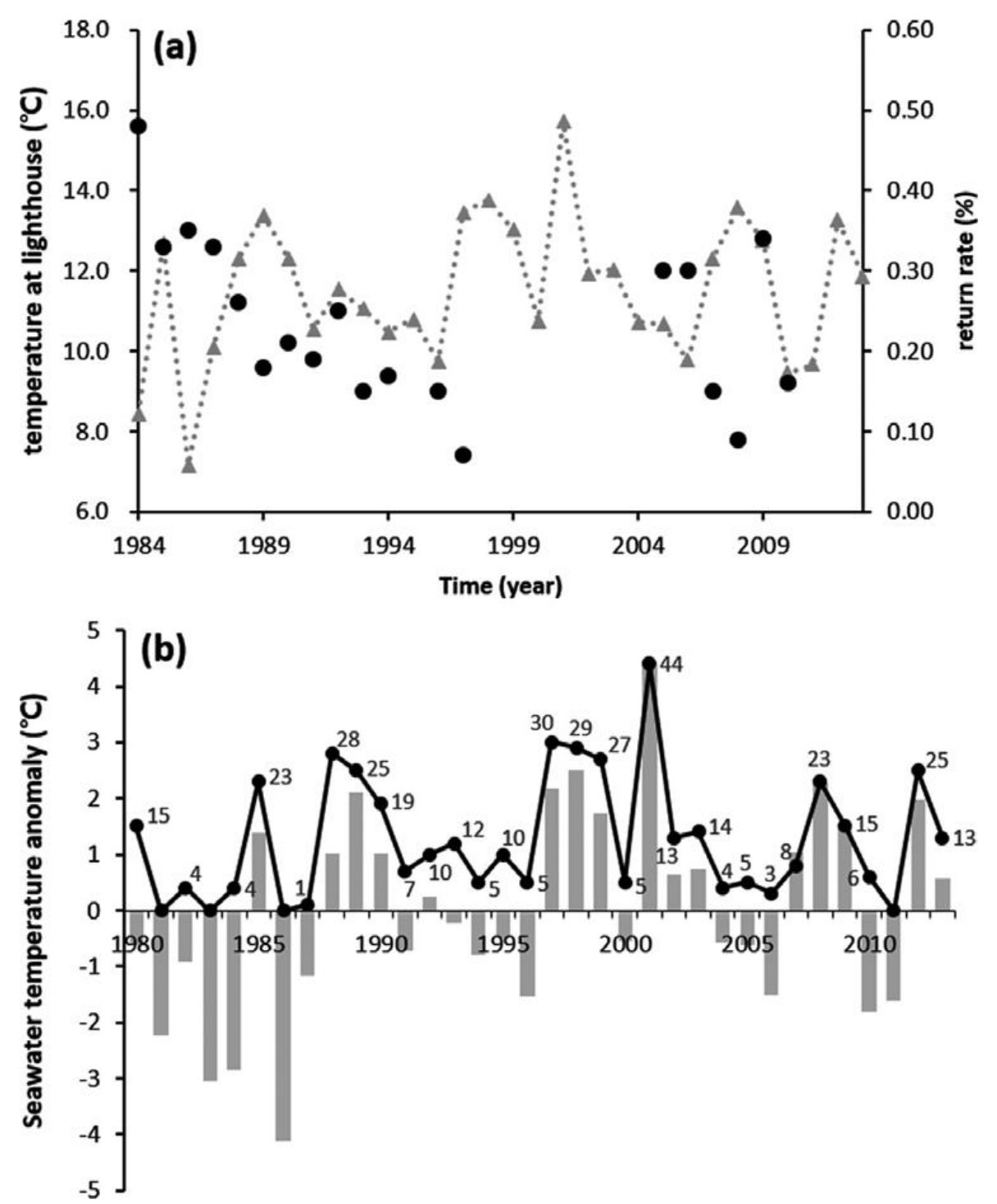

Fig. 3. Time-series of (a) Return rate (\%, dot) of chum salmon released from Yangyang hatchery and mean seawater temperature anomalies in April-May (line), and (b) Mean seawater temperature anomalies (bar) and the number of days (line) exceeding $14^{\circ} \mathrm{C}$ in daily mean at Sokcho Lighthouse in April-May.

The return rates of Korean chum salmon released from the Yangyang hatchery in a specific year were generally low ranging from $0.1 \%$ to $0.5 \%$ (Fig. 3a). The new estimation of return rate for Korean chum salmon was slightly lower than a former estimation which was based on the assumption of Age-4 return, although they showed 
similar trends $(r=0.716, p<0.01)$. A return rate of Korean chum salmon seemed to be linked with the seawater temperature of coastal waters during their first year of ocean life. Though the general trend seems to be parallel during the mid-1980s to mid-1990s, the statistical analysis on the seawater temperature at the lighthouse during April and May and the return rate of chum salmon released in a specific year indicates a significant $r$ value $(r=-$ $0.492 *)$ at the 0.05 level. Coastal temperature observation at Sokcho Light House indicated that the largest negative anomalies that occurred in the early-mid 1980s matched with the high return rate of chum salmon. As the average lighthouse seawater temperature in April through May showed, lighthouse seawater temperature in April also showed a significant correlation $(r=-0.486, p<0.05)$ with return rate. Also, the high numbers in days exceeding $14^{\circ} \mathrm{C}$ in April and May appeared mostly in the 1990s through to the 2000s (Fig. 3b), which means that warm ocean temperature may cause the high mortality of chum salmon fry in coastal areas. Although there was no statistical significance in the 5\% level between return rate and SST observation in ocean monitoring stations or the number of days exceeding $14^{\circ} \mathrm{C}$, correlations were relatively high. Due to the lack of data collection, we cannot estimate the return rate during the 1998-2004 period.

\section{REFERENCES}

Francis RC, SR. Hare. 1994. Decadal scale regime shifts in the large marine ecosystems of the North-east pacific: a case for historical science. Fish Oceanogr. 3:279-291

Hare SR, NJ. Mantua. 2000. Empirical evidence for North Pacific regime shifts in 1977 and 1989. Prog. Oceanogr. 47:103-145

McKinnell, S.M. and M.J. Dagg. (Editors). 2010. Marine Ecosystems of the North Pacific Ocean, 2003-2008. PICES Sp. Pub. 4: 393 p.

Seo H, S. Kim, K. Seong, S. Kang. 2006. Variability in scale growth rates of chum salmon (Oncorhynchus keta) in relation to climate changes in the late 1980s. Prog. Oceanogr. 68:205-216

Rodionov SN. 2005. Detecting regime shifts in the mean and variance: methods and specific examples. In: Velikova V, Chipev N (eds) Large-scale disturbances (regime shifts) and recovery in aquatic ecosystems: challenges for management toward sustainability. UNESCO-ROSTE/BAS Workshop on Regime Shifts, Varna, Bulgaria, 14-16 June 2005, pp 68-72 